Article

\title{
Exploring Critical Variables That Affect the Policy Risk Level of Industrial Heritage Projects in China
}

\author{
Ping Guo ${ }^{1} \mathbb{C}$, Huimin $\mathrm{Li}^{1}$, Guangmin Zhang ${ }^{1}$ and Yang Zhang ${ }^{2, *}$ \\ 1 School of Civil Engineering, Xi'an University of Architecture and Technology, Xi'an 710055, China; \\ guoping@xauat.edu.cn (P.G.); lihuimin@xauat.edu.cn (H.L.); zhangguangmin@xauat.edu.cn (G.Z.) \\ 2 School of Management, Xi' an University of Architecture and Technology, Xi'an 710055, China \\ * Correspondence: zhangyang@xauat.edu.cn
}

Received: 18 September 2019; Accepted: 27 November 2019; Published: 2 December 2019

\begin{abstract}
With the rapid development of the transformation and urbanization of Chinese social structures, more and more industrial heritage renewal projects are emerging. However, there are significant policy risks associated with Chinese industrial heritage renewal projects. Through a literature review, a total of 20 policy risk factors were determined, and a total of 10 industrial heritage renewal project managers in six regions nationwide conducted a pilot study. A questionnaire survey was conducted to collect 398 evaluations of these 20 risk factors from relevant professionals. Secondly, through confirmatory factor analysis, a six-part policy risk assessment model was established. The results indicated that the critical variables that affect the policy risk level were: (1) industry maturity, (2) tax policy, (3) financial freedom, (4) the rule of law, (5) local market size, and (6) local market experience. Moreover, there are significant opportunities and policy risks in Chinese industrial heritage renewal projects, and appropriate strategies can capture these opportunities and mitigate risks. As there are few pieces of research on the policy risks of industrial heritage renewal projects in China, this study has a certain reference significance for the policy risk management of industrial heritage renewal projects in China.
\end{abstract}

Keywords: policy risks; industrial heritage; risk assessment; structural equation model

\section{Introduction}

Through large-scale and planned construction, China has become one of the largest global economic powers with the greatest potential for development. With the progress of China's urbanization and the adjustment of its urban function layout, industrial heritage is also reflecting this new value orientation more clearly $[1,2]$.

The China State Council has put forward several suggestions to further strengthen urban planning and construction management [3], aiming to optimize urban and rural layouts, improve urban functions, and carry out urban repair and organic renewal in an orderly manner. To this end, various regions in China have put forward relevant policies regarding industrial heritage, including the Northeast, East, North, South, Southwest, and Northwest regions.

The operation environment of industrial heritage renewal projects is closely related to the local economic and political conditions [4]. For domestic enterprises, industrial heritage renewal projects have both opportunities and risks. Therefore, a comprehensive understanding of policy risks is essential for making appropriate business decisions [5]. Policies, laws, and regulations are in the initial stage of the industrial heritage renewal project. Due to land ownership, approval processes, benefit distribution, and other issues, policy risks have been relatively high, resulting in the slow development and progress of the project. Policy risk refers to the unexpected consequences and risks caused by market price fluctuations, which depend on the changes in national macro-policies (such as monetary 
policy, fiscal policy, industrial policy, regional development policy, etc.). Compared with common new projects, industrial heritage renewal projects have higher public attention and policy sensitivity. The recreational industrial park Redtory in Guangzhou, China, provides us with a powerful testimony. Its predecessor was the Guangzhou cannery factory founded in 1956. In 2009, it was reclaimed as a recreational industrial park. However, the Redtory fell into a dispute over land property and was then reclaimed by the government after 10 years of prosperity. It is now in ruins [6] and in danger of being permanently lost. We are worried about whether the past glory will last. As a result, the operation of these projects is influenced by social, economic, cultural and legal factors seriously. Besides this, the relationship between national policy risk and regional policy risk has distinct characteristics in different regions. In China the third national cultural relics census, even though the industrial heritage was included in the scope of the census as an important content [7], Wuhan's industrial heritage resources were dying out rapidly because of the inexperience of the local market [8]. The Wuhan heavy machinery factory and boiler factory were facing a similar experience to that of the Redtory. Due to improper handling, they were sold to real estate companies. Therefore, policy risk research must be linked with a specific background, including the regional background and industry background [9]. However, policy risks related to the renewal of industrial heritage, especially those related to the region, have been largely ignored in previous studies.

Based on the above, this paper attempts to,

(1) Reveal the inherent law of risks of Chinese industrial heritage policy.

(2) Explore variables affecting the policy risk level of China's industrial heritage projects.

(3) Analyze the internal components of variables and their importance.

(4) Assess the level of policy risks of Chinese industrial heritage projects and explore the corresponding risks and opportunities in the Chinese market.

The research framework of the full text is reflected in the flowchart in Figure 1.

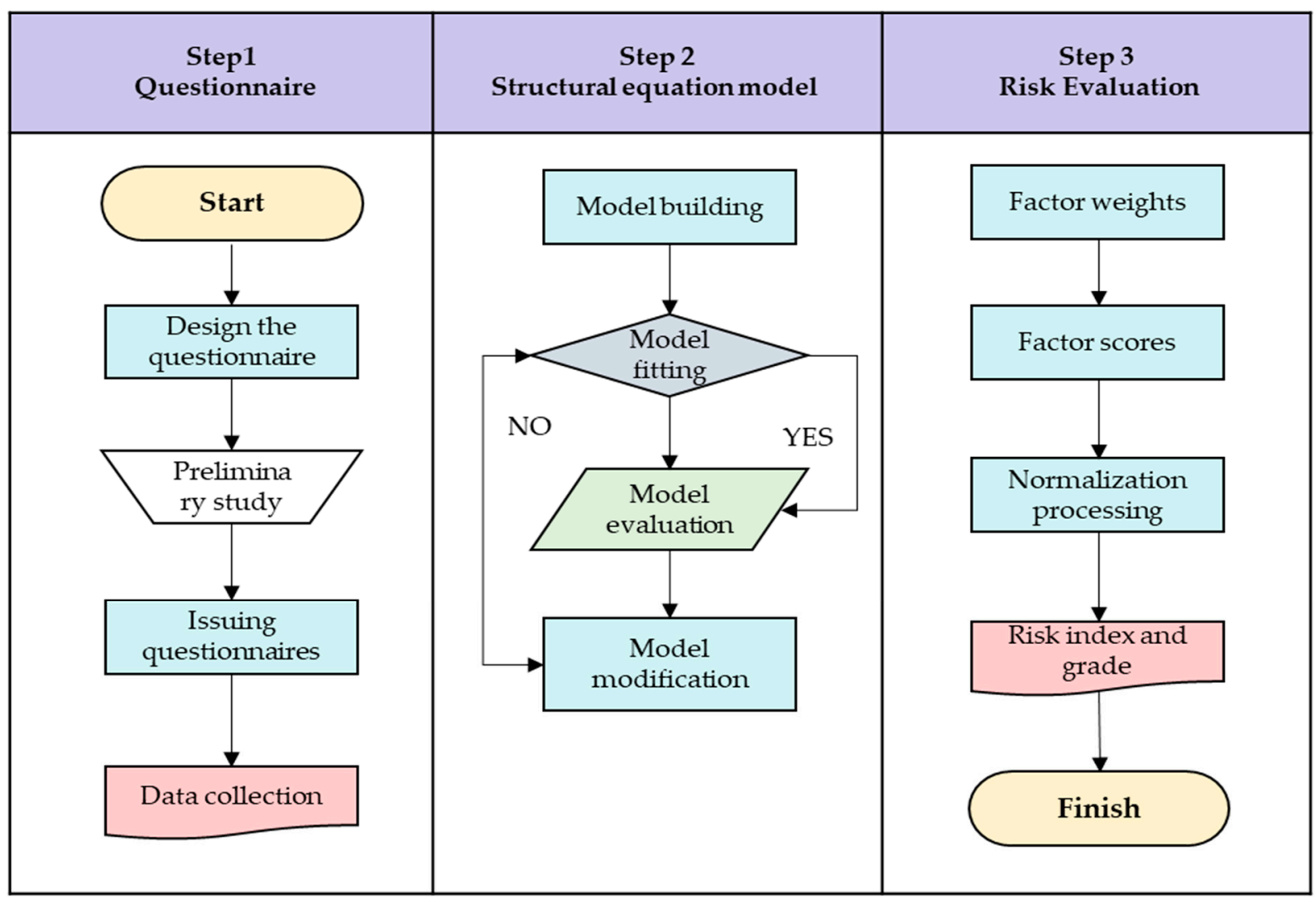

Figure 1. Flow chart of the policy risk study. 


\section{Literature Review}

Policy risk is an important source of social contradiction or social stability risk and has attracted a great deal of attention from governments and academia. Policy risk refers to various factors that exist in the process of policy formulation and implementation, which come from the internal and external environment of the policy system, and may lead to the failure of the expected ideal goal of policy implementation or policy failure [10]. Due to the catastrophic impact caused by major policy mistakes or failures, many countries around the world have responded to policy risks by establishing crisis management mechanisms, which reflects a certain consensus regarding the management of policy risk factors. Common sources of policy risk include policy inconsistency, changes in laws and regulations, etc. [11].

Treating the variables that lead to risk as risk factors, regional risks are usually manifested as major changes in regional policies and regulations, regional economic performance, regional environmental deterioration, a decline in regional internal operation and management level, deterioration of regional credit asset quality, and so on [12]. Regional economic performance could be a harbinger of government policy uncertainty and social instability and is therefore considered an important factor in policy risk. In addition, under the Chinese existing political framework, state administrative organs and legislatures also formulate and implement policies from different dimensions. The operation of an industrial heritage renewal project is closely related to the state's macro-control of the region, and the resulting risks cannot be ignored.

Risk management is the key factor to achieve project management goals [13]. Successful risk management not only reduces risk but also helps to achieve and maintain competitive advantages, with the aim of improving the overall effectiveness of industrial heritage renewal projects [14]. Policy risk assessment refers to the legitimate and reasonable assessment of the possible risks and damaged groups in the policy, which are the important plans and policies concerning economic and social development and also involve the vital interests of the people to provide a basis for scientific decision-making [15]. Risk levels are usually derived from two dimensions: the probability of occurrence and the severity of the consequences. Risk factors assess policy risks such as PRR (policy risk rating), BER (business environment risk intelligence), and IPER (index of political and economic risk).

An increasing body of research has tried to shed light on the reasons behind such differences in policy effectiveness. While early contributions in this strand of research have highlighted the importance of sufficiently high support levels and the long-term stability of policy frameworks, more recent work is drawing attention to the importance of policy risk. The existing policy risk research is mainly related to general new construction projects [14], and little attention has been paid to the policy risks associated with industrial heritage renewal projects. Published policy risk reports, such as the International Country Risk Group (ICRG)'s policy risk rating, focus only on political, financial, economic, social, and institutional risks in specific countries [16]. Therefore, it is not possible to identify unique risks or opportunities determined by the specific circumstances of the industrial heritage renewal industry and the relationship between national and regional policies.

\section{Research Methods}

\subsection{Political Risk Assessment Process}

How to use specific methods to achieve the research objectives of this paper is worth thinking about. Fortunately, the latest ISO 31000:2018 standard gives us an answer [17]. According to the risk assessment procedures given in ISO 31000, appropriate adjustments were made in accordance with the characteristics of the regional risk assessment. Finally, the risk assessment framework was provided in this paper was given. The study was broken into five steps: (1) risk identification, (2) risk analysis, (3) establishing a model for risk evaluation, (4) exploring opportunities and challenges, and (5) formulating coping strategies. The main steps are shown in Figure 2. 


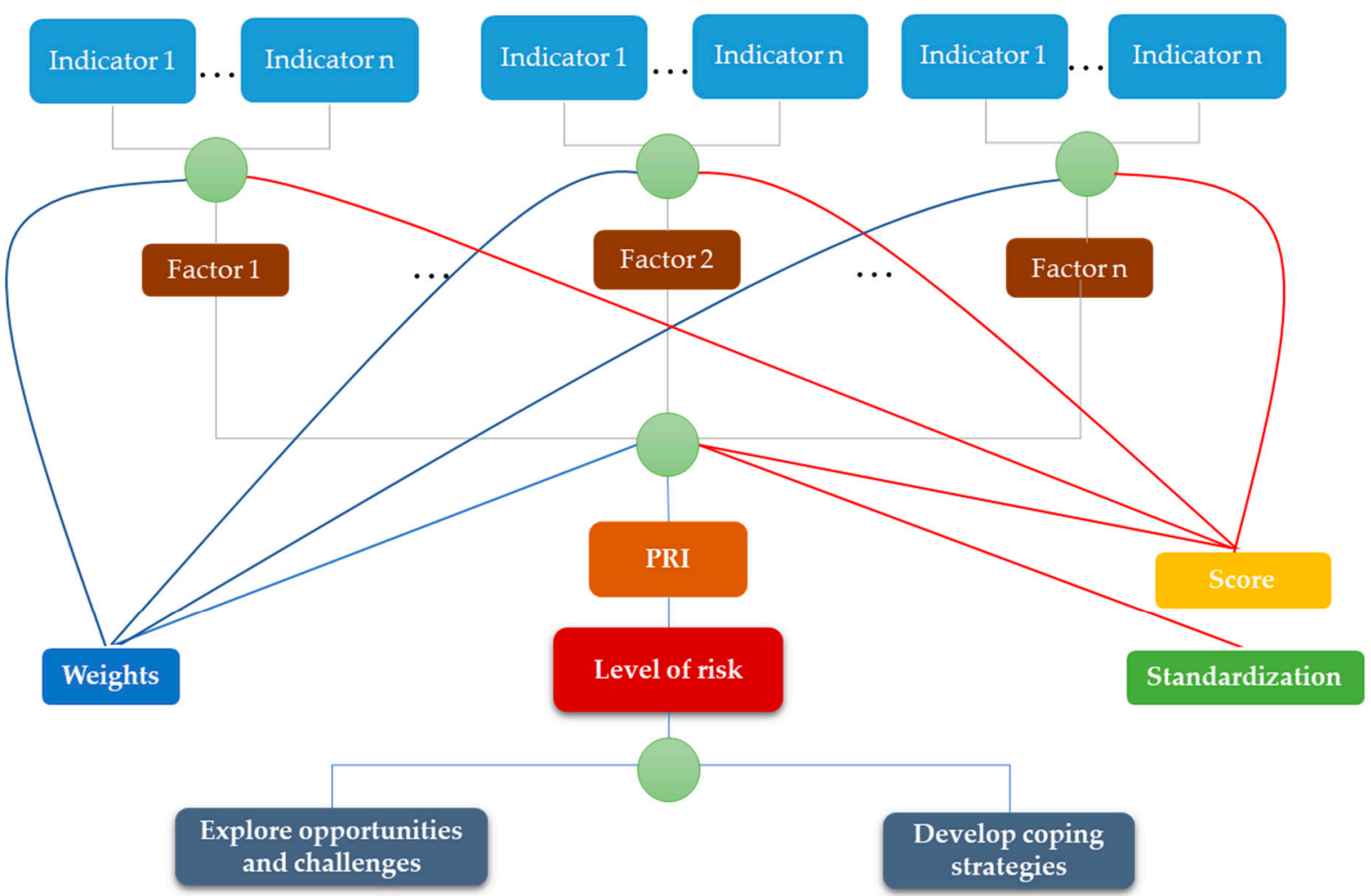

Figure 2. Procedures for assessing policy risks.

\subsection{Factor Identification and Survey}

Through a comprehensive literature review, the authors identified 20 policy risk factors. The risk factors and related literature were listed in Table 1 , and these include variables from different perspectives such as political violence, political stability and the rule of law. To verify the rationality of these factors, the authors conducted a preliminary investigation. Ten people with more than 20 years of experience were invited to take up positions in the industrial heritage renewal project, including management posts, design posts, construction posts, and operation posts. In the design of the questionnaire, in order to improve the validity and reliability of the questionnaire as much as possible, the authors tried to find the classic relevant questionnaires in relevant fields or other questionnaires, which have been successfully applied in relevant research and modified them to achieve the purpose of this study. All data were measured by Likert 7 scales $[18,19]$. The semantic difference method or measurement method was adopted in the questionnaire. All respondents were asked to evaluate the correlation between policy risk and each risk factor on a scale of $1-7$, with " 1 " representing the least relevant and " 7 " the most relevant. To ensure that respondents had the same definition or description of these factors, a brief introduction was attached to the questionnaire.

The research group took many provinces and cities across the country as the collection points of survey data, and its research energy and capacity were limited, which represented the impact of policy risks in various regions of China on industrial heritage renewal projects. In the early stages of the investigation, 10 investigators were trained in the basics of the project. From 16 February to 16 March 2019, we randomly selected the streets, central squares, shopping malls, and parks around the industrial heritage renewal project for investigation. The location map of the survey is shown in Figure 3, and Beijing was taken as an example to mark the distribution location of the questionnaire. A total of 553 questionnaires were issued, and 398 valid questionnaires were collected, with an effective questionnaire rate of $72.0 \%$. The basic information of survey participants is shown in Table 2, and the regional distribution and occupational characteristics of effective samples are shown in Table 3. Everyone who took part in the survey was given a souvenir. 
Table 1. Risk factors associated with industrial heritage projects.

\begin{tabular}{|c|c|c|}
\hline No. & Variables & Literature \\
\hline V1 & Geopolitical & $\begin{array}{l}\text { Yuzhe Wu et al. (2013), Barrie Needham (2013), David C (2001), Gao Boyang (2013), Rao et al. } \\
\text { (2005), De La Torre and Neckar (1988) }\end{array}$ \\
\hline V2 & Political violence & David C (2001), Rao et al. (2005), Deng and Low (2014) \\
\hline V3 & Political stability & David C. (2001), Gao Boyang (2013), Howell and Chaddick (1994), Ashley and Bonner (1987) \\
\hline V4 & The rule of law & $\begin{array}{l}\text { Ademola K et al. (2007), G.W. Page (2004), David C. (2001), Gao Boyang (2013), Peter Van } \\
\text { Gossum (2010) }\end{array}$ \\
\hline V5 & Government efficiency & $\begin{array}{l}\text { Yuzhe Wu et al. (2013), G.W. Page (2006), David C (2001), Gao Boyang (2013), Peter Van } \\
\text { Gossum (2010) }\end{array}$ \\
\hline V6 & Control of corruption & $\begin{array}{l}\text { Gao Boyang (2013), Peter Van Gossum (2010), Howell and Chaddick (1994), De La Torre and } \\
\text { Neckar (1988) }\end{array}$ \\
\hline V7 & Land policy & $\begin{array}{c}\text { Ademola K et al. (2007), Jieming Zhu (2000), G.W. Page (2006), Andrew Churcha (2007), Gao } \\
\text { Boyang (2013) }\end{array}$ \\
\hline V8 & Tax policy & Taylor (1993), Jieming Zhu (2000), G.W. Page (2006), Andrew Churcha (2007) \\
\hline V9 & Investment freedom & Jieming Zhu (2000), Gao Boyang (2013) \\
\hline V10 & Financial freedom & Jieming Zhu (2000), Rao et al. (2005), Yaprak and Sheldon (1984), Ashley and Bonner (1987) \\
\hline V11 & Free trade & Ademola K et al. (2007), Yuzhe Wu et al. (2013), Gao Boyang (2013) \\
\hline V12 & Industry maturity & $\begin{array}{l}\text { Barrie Needham (2013), Rao et al. (2005), Alon and Herbert (2009), De La Torre and Neckar } \\
\text { (1988), Yaprak and Sheldon (1984) }\end{array}$ \\
\hline V13 & Industry rate of return & $\begin{array}{l}\text { Barrie Needham (2013), Al Khattab et al. (2007), De La Torre and Neckar (1988), Yaprak and } \\
\text { Sheldon (1984) }\end{array}$ \\
\hline V14 & Local market size & Yuzhe Wu et al. (2013), G.W. Page (2006), Gao Boyang (2013) \\
\hline V15 & $\begin{array}{l}\text { Local market } \\
\text { experience }\end{array}$ & Yuzhe Wu et al. (2013), G.W. Page (2006), Gao Boyang (2013) \\
\hline V16 & $\begin{array}{c}\text { Regional } \\
\text { unemployment rate }\end{array}$ & Salvador (2005), Hastak and Shaked (2000), Rao et al. (2005) \\
\hline V17 & Regional GDP & $\begin{array}{l}\text { Ademola K et al. (2007), Geoghegan et al. (2001), Jieming Zhu (2000), Yuzhe Wu et al. (2013), } \\
\text { Salvador (2005) }\end{array}$ \\
\hline V18 & $\begin{array}{l}\text { Adaptation to the } \\
\text { regional economy }\end{array}$ & Ademola K et al. (2007), Salvador (2005), David C. (2001), Peter Van Gossum (2010) \\
\hline V19 & $\begin{array}{l}\text { Adaptation to the } \\
\text { regional culture }\end{array}$ & Ademola K et al. (2007), David C. (2001), Peter Van Gossum (2010) \\
\hline V20 & Public satisfaction & Yuzhe Wu et al. (2013), David C (2001), Peter Van Gossum (2010) \\
\hline
\end{tabular}

Table 2. Study sample description sheet.

\begin{tabular}{ccc}
\hline Variable Name & Variable Description & Sample Count \\
\hline \multirow{2}{*}{ Age } & 30 and under & 243 \\
\cline { 2 - 3 } & Above 30 & 155 \\
\hline \multirow{2}{*}{ Gender } & Male & 181 \\
\cline { 2 - 3 } & Female & 217 \\
\hline \multirow{2}{*}{ Level of education } & Below bachelor degree & 25 \\
\cline { 2 - 3 } & Bachelor degree and above & 373 \\
\hline
\end{tabular}

Note: Personal privacy questions are not mandatory. 

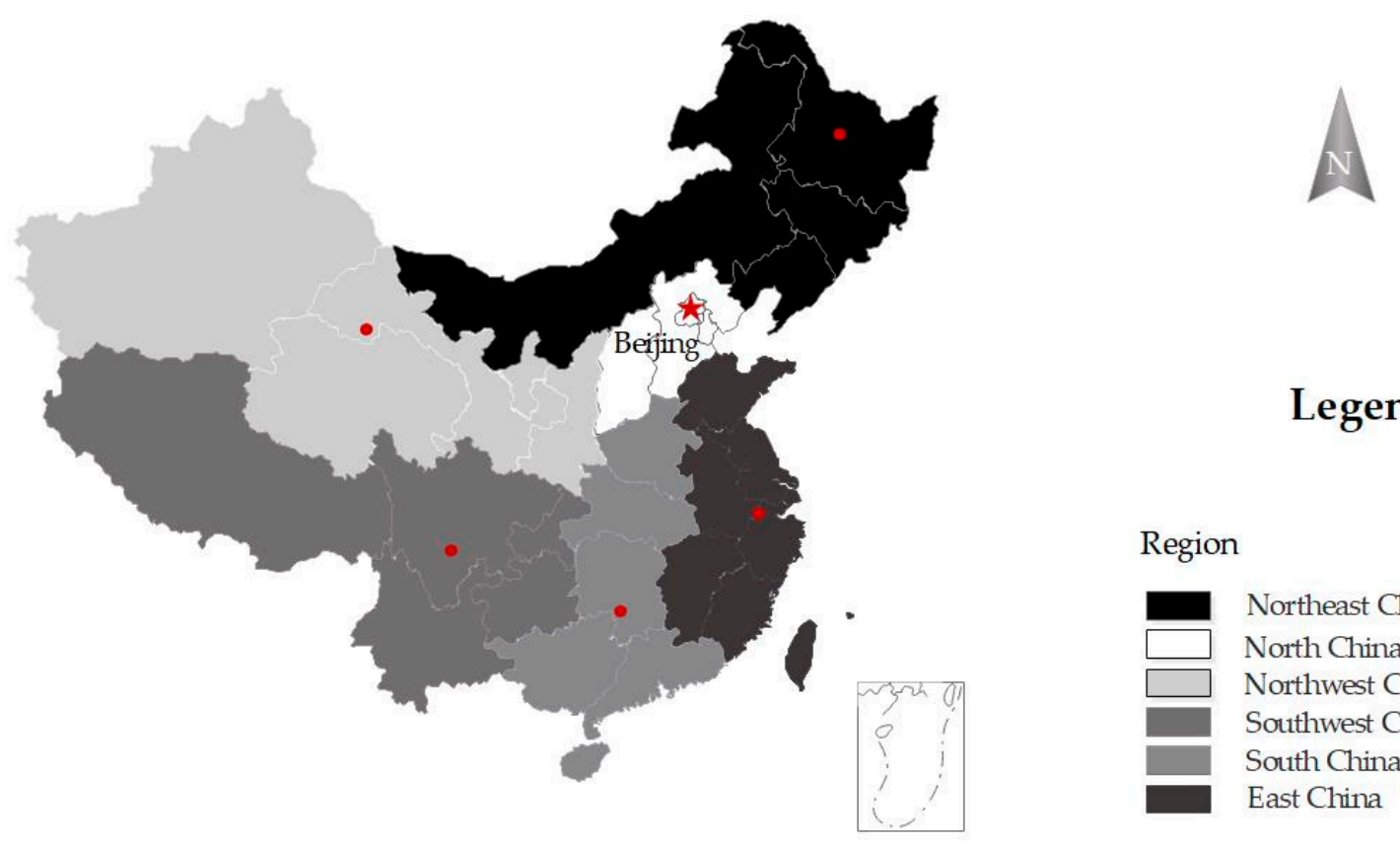

\section{Legend}

(a)

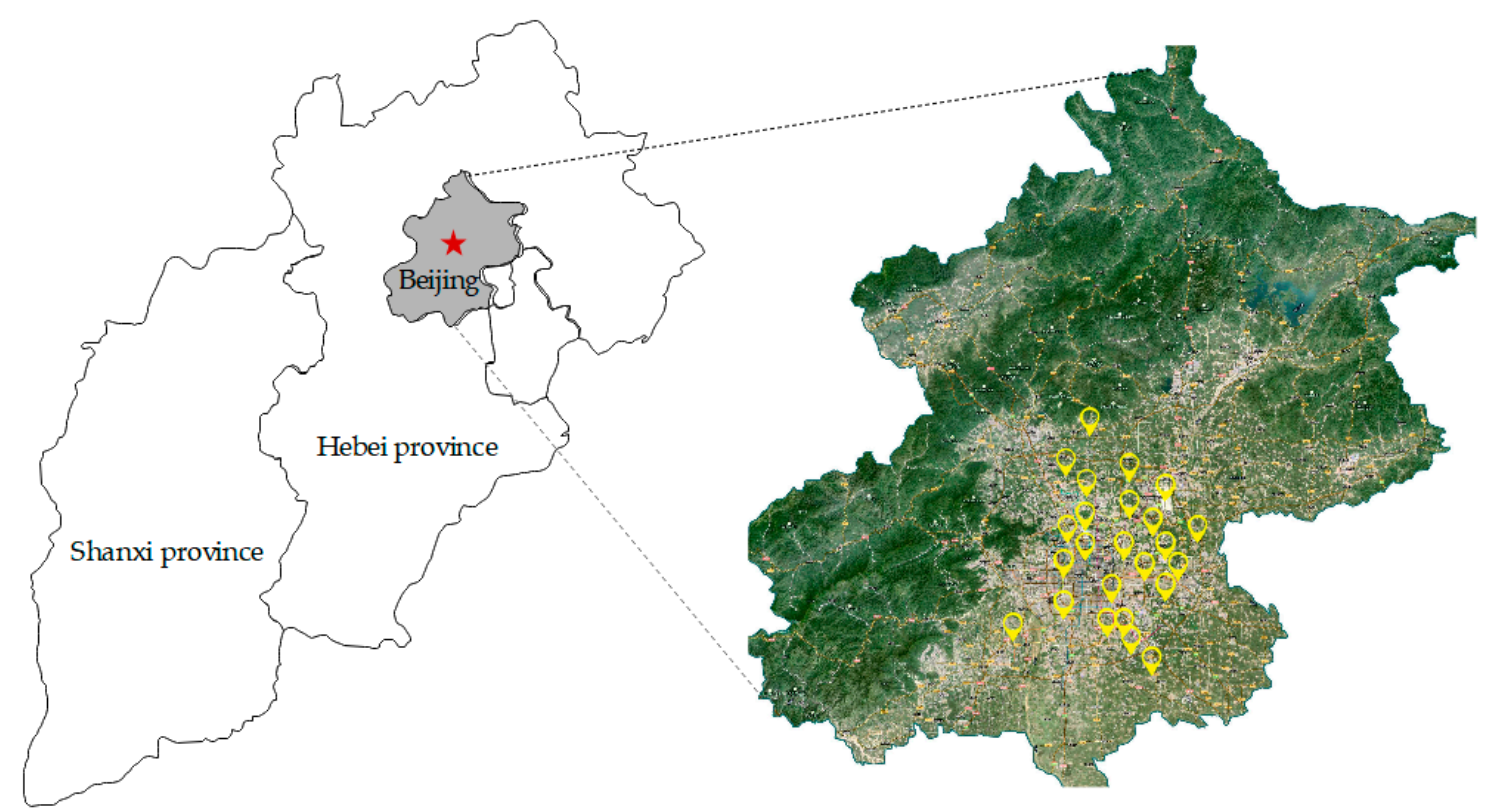

(b)

Figure 3. Location of policy risk research. Note: (a) survey area map; (b) take Beijing for example. 
Table 3. Profile of valid responses in the survey.

\begin{tabular}{cccccccccc}
\hline \multirow{2}{*}{$\begin{array}{c}\text { Working Regional } \\
\text { Segment }\end{array}$} & PC & DO & CO & SU & GA & AB & AI & OIE & Others \\
\cline { 2 - 10 } & $\mathbf{2 9}$ & $\mathbf{5 7}$ & $\mathbf{3 8}$ & $\mathbf{1 7}$ & $\mathbf{4 7}$ & $\mathbf{1 0}$ & $\mathbf{7 1}$ & $\mathbf{6 1}$ & $\mathbf{6 8}$ \\
\hline Northeast & 4 & 7 & 3 & 3 & 6 & 1 & 3 & 7 & 4 \\
\hline East China & 9 & 11 & 8 & 5 & 5 & 3 & 20 & 19 & 11 \\
\hline North China & 6 & 12 & 10 & 5 & 9 & 1 & 9 & 9 & 14 \\
\hline South China & 8 & 20 & 5 & 2 & 10 & 4 & 16 & 17 & 17 \\
\hline Southwest & 1 & 1 & 3 & 1 & 2 & 0 & 3 & 3 & 5 \\
\hline Northwest & 1 & 6 & 9 & 1 & 15 & 1 & 20 & 6 & 17
\end{tabular}

Note: Due to space restrictions, the contents in the first row of the Table are expressed in abbreviated form, with the specific meanings explained as follows: PC: property company; DO: design organization; CO: construction organization; SU: supervision unit; GA: Governmental agencies; AB: advisory body; AI: academic institution; OIE: original industrial enterprise.

When conducting the questionnaire survey, it is easy to produce some inevitable misunderstandings, such as errors caused by data interference and random answers given by respondents. In order to minimize the error of the questionnaire, we adopted the preprocessing method. Firstly, several people were invited to fill in the questionnaire to ensure the readability and universality of the questionnaire, indicating that the questionnaire is suitable for large-scale distribution and testing. Secondly, the purpose and use of this survey was stated to the respondents on the first page of the questionnaire. The meaning of "industrial heritage" and other professional terms should be explained to the respondents through the combination of language and pictures. Before the survey, staff were trained, including in filling out real-name survey documents and dressing uniformly, in order to strengthen the standardization and pertinence of the survey activities. During the investigation, the staff maintained neutrality and did not interfere with or induce the judgment of the investigated parties. At the same time, the staff asked the respondents questions and randomly adjusted the order of the survey questions three times in order to minimize the possibility of the answers being influenced by the order of the survey questions. After the survey, in order to collect as many effective questionnaires as possible, the staff carefully checked whether there were blank items in the survey questionnaire. Under the condition of not encroaching upon personal privacy, the staff requested the respondents to improve their answers in the blank section.

\subsection{Assessment Model Establishment}

In the field of behavioral social sciences, there are many hypothetical constructs that cannot be directly measured or observed. These hypothetical constructs are a trait or abstract concept, which cannot be directly known, but can only be indirectly reflected in scales or observed actual index values [20]. Through literature analysis as shown in Table 1, we summarized five potential variables that affect the policy risks of industrial heritage projects. Referred to the indicators set by scholars to measure these potential variables, we obtained 20 observation indexes. In the establishment of the structural equation model, according to the suggestions of Hair et al., the ratio of samples to observed values and the variables of the structural equation model should be between 1:10 and 1:15, and a number of samples between 200 and 400 is appropriate [21]. As a result, a total of five potential variables and 20 questions were included, meaning that 398 samples were used to develop the model to meet the requirements of sample size.

Cronbach's $\alpha$ coefficient was used to determine whether the reliability of the questionnaire reached the relevant standards. Firstly, the problems that did not meet the reliability requirements were eliminated, and then the reliability of the remaining problems was analyzed again. The results are shown in Table 4 . Cronbach's $\alpha$ value exceeds the standard of 0.7 , indicating that the questionnaire 
has good reliability. In terms of the validity test, we used the most widely used test items in this field, namely convergent validity and discriminant validity.

Table 4. Reliability and validity convergence table of policy risk factors survey questionnaire.

\begin{tabular}{|c|c|c|c|c|c|c|c|c|c|}
\hline \multirow{2}{*}{ Latent Variable } & \multirow{2}{*}{ Title } & \multicolumn{4}{|c|}{ Estimation of Parameter Significance } & \multirow{2}{*}{$\begin{array}{c}\begin{array}{c}\text { Factor } \\
\text { Loading }\end{array} \\
\text { Std. }\end{array}$} & \multirow{2}{*}{$\begin{array}{c}\text { Question } \\
\text { Loading } \\
\alpha\end{array}$} & \multirow{2}{*}{$\begin{array}{c}\text { Composite } \\
\text { Reliability }\end{array}$} & \multirow{2}{*}{$\begin{array}{c}\begin{array}{c}\text { Convergent } \\
\text { Validity }\end{array} \\
\text { AVE }\end{array}$} \\
\hline & & Unstd & S.E. & $t$-Value & $p$ & & & & \\
\hline \multirow{3}{*}{ Social Politics } & SP1 & 1.000 & & & & 0.756 & 0.882 & \multirow{3}{*}{0.821} & \multirow{3}{*}{0.605} \\
\hline & SP2 & 1.224 & 0.127 & 9.637 & $* * *$ & 0.817 & 0.882 & & \\
\hline & SP3 & 1.464 & 0.162 & 9.008 & $* * *$ & 0.759 & 0.880 & & \\
\hline \multirow{3}{*}{$\begin{array}{l}\text { Institutional } \\
\text { Quality }\end{array}$} & IQ1 & 1.000 & & & & 0.827 & 0.878 & \multirow{3}{*}{0.834} & \multirow{3}{*}{0.627} \\
\hline & IQ2 & 0.906 & 0.082 & 11.015 & $* * *$ & 0.802 & 0.880 & & \\
\hline & IQ3 & 0.768 & 0.093 & 8.291 & $* * *$ & 0.744 & 0.884 & & \\
\hline \multirow{5}{*}{ Economic Policy } & EP5 & 1.000 & & & & 0.759 & 0.884 & \multirow{5}{*}{0.901} & \multirow{5}{*}{0.647} \\
\hline & $\mathrm{EP} 4$ & 1.101 & 0.155 & 7.108 & $* * *$ & 0.828 & 0.884 & & \\
\hline & EP3 & 1.258 & 0.177 & 7.108 & $* * *$ & 0.764 & 0.883 & & \\
\hline & EP2 & 1.181 & 0.177 & 6.682 & $* * *$ & 0.855 & 0.882 & & \\
\hline & EP1 & 1.577 & 0.227 & 6.952 & $* * *$ & 0.810 & 0.880 & & \\
\hline \multirow{4}{*}{$\begin{array}{l}\text { Industry } \\
\text { Specifics }\end{array}$} & IS1 & 1.000 & & & & 0.876 & 0.882 & \multirow{4}{*}{0.896} & \multirow{4}{*}{0.683} \\
\hline & IS2 & 1.275 & 0.150 & 8.511 & $* * *$ & 0.779 & 0.881 & & \\
\hline & IS3 & 1.263 & 0.138 & 9.183 & $* * *$ & 0.826 & 0.881 & & \\
\hline & IS4 & 1.292 & 0.146 & 8.833 & $* * *$ & 0.821 & 0.881 & & \\
\hline \multirow{5}{*}{$\begin{array}{c}\text { Regional } \\
\text { Characteristics }\end{array}$} & RC5 & 1.000 & & & & 0.798 & 0.881 & \multirow{5}{*}{0.893} & \multirow{5}{*}{0.626} \\
\hline & $\mathrm{RC} 4$ & 0.786 & 0.094 & 8.389 & $* * *$ & 0.795 & 0.883 & & \\
\hline & RC3 & 0.984 & 0.100 & 9.881 & $* * *$ & 0.793 & 0.880 & & \\
\hline & RC3 & 0.809 & 0.096 & 8.406 & $* * *$ & 0.749 & 0.885 & & \\
\hline & $\mathrm{RC} 1$ & 0.601 & 0.099 & 6.061 & $* * *$ & 0.819 & 0.885 & & \\
\hline
\end{tabular}

Note: ${ }^{* * *}$ Significant at $p<0.001$.

According to Fornell and Larcker's study, the convergence validity test should focus on such indicators as the standardized factor loading, combined reliability (CR), and average variance extraction (AVE). According to the calculation results in Table 3, the standardized factor loading value was greater than 0.6 , the CR value was above 0.7 , and the AVE value was greater than or close to 0.5 , indicating the significance of the non-standardized test. All the above were in line with Fornell and Larcker's recommendations, so we could determine that each potential variable had good convergence [22].

The results of the discriminant validity test are shown in Table 5. The effective method of the discriminant validity test was used to determine whether the square root of the AVE value relative to potential variables was greater than all other potential variables and other correlation coefficients, which could be proved by the research results of Fornell and Larcker [23,24]. Therefore, it was not difficult to see that the data in Table 5 indicates that the potential variables in our questionnaire had good discriminant validity. 
Table 5. Discrimination validity table of the model.

\begin{tabular}{ccccccc}
\hline & AVE & $\begin{array}{c}\text { Social } \\
\text { Politics }\end{array}$ & $\begin{array}{c}\text { Institutional } \\
\text { Quality }\end{array}$ & $\begin{array}{c}\text { Economic } \\
\text { Policy }\end{array}$ & $\begin{array}{c}\text { Industry } \\
\text { Specifics }\end{array}$ & $\begin{array}{c}\text { Regional } \\
\text { Characteristics }\end{array}$ \\
\hline Social Politics & 0.605 & 0.692 & - & - & - & - \\
\hline Institutional Quality & 0.627 & - & 0.778 & - & - & - \\
\hline Economic Policy & 0.647 & - & - & 0.887 & - & - \\
\hline Industry Specifics & 0.683 & - & - & - & 0.719 & - \\
\hline Regional Characteristics & 0.626 & - & - & - & - & 0.904 \\
\hline $\begin{array}{l}\text { Note: Bold indicates the square root of the average variance extraction (AVE) between latent variables, and the rest } \\
\text { is the Pearson correlation value between latent variables. }\end{array}$
\end{tabular}

The structural equation model is a statistical method used to analyze the relationship between variables based on the covariance matrix of variables, and it is an important tool for multivariate data analysis. When the structural equation model was used, the goodness of fit of the model must pass the test, which represents that the model established by us is closer to the real situation of samples. There are 10 widely-accepted fitting indexes in existing studies, namely chi-square, degrees of freedom (df), chi-square/df ratio, root-mean-square error of approximation (RMSEA), standardized root-mean-square residual (SRMR), goodness-of-fit index (GFI), adjusted GFI, normed fit index (NFI), the Tucker-Lewis index (TLI), and comparative fit index (CFI). This conclusion was verified by comparative of fit articles [24]. According to the above suggestions, this paper also adopted these 10 indicators for comparative analysis when verifying the goodness of fit of the model. After two rounds of model correction, the correlation of error terms was increased according to the correction index, and finally, an acceptable goodness of fit for the model was achieved. Specific fit indexes are shown in Table 6 below.

Table 6. Model fitting table.

\begin{tabular}{ccccccccccc}
\hline Fitting Index & Chi-square & df & CMIN/df & RMSEA & SRMR & GFI & AGFI & NFI & TLI & CFI \\
\hline Criteria & $\begin{array}{c}\text { The smaller } \\
\text { the better }\end{array}$ & $\begin{array}{c}\text { The larger } \\
\text { the better }\end{array}$ & $\begin{array}{c}1<\text { CMIN/df } \\
<3\end{array}$ & $<0.08$ & $<0.08$ & $>0.9$ & $>0.9$ & $>0.9$ & $>0.9$ & $>0.9$ \\
\hline Measurement value & 226.933 & 147 & 1.544 & 0.037 & 0.039 & 0.946 & 0.923 & 0.905 & 0.953 & 0.964 \\
\hline
\end{tabular}

Note: df: degrees of freedom; RMSEA: root-mean-square error of approximation; SRMR: standardized root-mean-square residual; GFI: goodness-of-fit index; AGFI: adjusted GFI; NFI: normalized fit index; TLI: Tucker-Lewis index; CFI: comparative fit index.

Therefore, the structural equation model has good fitting indexes, indicating that the model fits the data well.

The weights of each component and risk factors are calculated by the weighted average of their path coefficients. For the components, $M_{i}$ is the weight of I, and $N_{i}$ is the load $\left(W_{i}\right)$ of component $\mathrm{I}$ in the final standardized estimation model. For risk factors, $M_{i}$ is the weight of factor I and $N_{i}$ is the load $\left(W_{i}\right)$ of factor I in each component. Therefore, Equation (1) can be used as follows:

$$
M_{i}=\frac{N_{i}}{\sum_{i=1} N_{i}} .
$$

\subsection{Risk Assessment}

The policy risk assessment of industrial heritage renewal belongs to qualitative risk assessment. According to Isaac's suggestion, qualitative risk assessment is determined by the score and weight of each risk factor. The score of each component is equal to the weighted average score of its contained factors. The weight of each component is obtained by the results of the confirmatory factor analysis [25]. Scores for each factor are calculated using data provided in national reports or statements, including the ministry of commerce of China's national report issued in 2018 (SP1, IS1 IS4 RC3), the world bank 
governance index (SP3, IQ1-3), the heritage foundation 2016 index of economic freedom (EP3-5), the Chinese bureau of statistics data released in 2018 countries (EP1, EP2, IS3, RC1-2, RC4), PTS2016 political terror level (SP2), as well as IS2, which is measured by the industry's contribution to economic growth, and RC4, which is determined by residents' recognition of the industry.

Due to the different nature of each evaluation index, they usually have different dimensions and magnitudes. To ensure the reliability of the results, it is necessary to standardize the original index data. After standardized processing, data of different dimensions are uniformly expressed by a 100-point score; that is, $0-100$ points. The value of the policy risk index (PRI) is expressed by that the full score minus the weighted average of each sub-score in order to objectively define the policy risk level of each region in China. This paper consulted scholars and experts in the study of industrial heritage and policy risks. Considering the frequency and possible adverse effects of risks, it also classified them according to the principle of average. After quantifying the level of policy risk, this paper classified three levels, namely, low level $(<20)$, medium level $(21-40)$, and high level $(>40)$, so as to understand the meaning of policy risk index more intuitively.

In addition, IBM SPSS Statistics ver.20.0 software is used to measure the policy risk level of each region, and cluster analysis is used to classify each region, making individuals within the same category as homogenous as possible, with the highest possible heterogeneity between categories. Clustering is a typical algorithm for unsupervised learning, with the aim of exploring and discovering certain patterns for discovering common groups. In this paper, the K-means cluster analysis method was adopted, with the score of each component and the policy risk index as the measurement indicators, and the output results belonging to the same category would have the same policy risk level.

\section{Results and Discussion}

In this section, the aim of the paper was to identify and analyze the policy risk factors that have a critical effect on the regeneration of industrial buildings. According to the principle of the structural equation model, the load coefficients of observed variables reflect the importance of their relationship with latent variables. As shown in Table 1 , the load coefficients of all variables varied from 0.744 to 0.876, which means that the respondents consider, in general, all of variables was critical to the policy risk of industrial buildings. Then, we sorted the load coefficients of each observation variable, and the results showed that the first six variables were: (1) industry maturity (IS1), (2) tax policy (EP2), (3) financial freedom (EP4), (4) the rule of law (IQ1), (5) local market size (IS3), and (6) local market experience (IS4). They are the key policy risk factors for industrial heritage renewal projects that we have been exploring. The above variables are discussed in detail from a global perspective in the following elaboration.

\subsection{Risk Grades of the Districts}

After several rounds of modification, the model achieves a good fitting effect, and the path coefficient is taken as a weight basis. The weight calculation results of each factor and component are shown in Table 7. 
Table 7. Risk factor weight summary. (a) Risk factor weight summary (macro-factors). (b) Risk factor weight summary (micro-factors).

\begin{tabular}{|c|c|c|c|c|c|c|c|c|c|c|}
\hline \multicolumn{11}{|c|}{ (a) } \\
\hline \multicolumn{3}{|c|}{ SP } & \multicolumn{3}{|c|}{ IQ } & \multicolumn{5}{|c|}{ EP } \\
\hline \multicolumn{3}{|c|}{0.236} & \multicolumn{3}{|c|}{0.169} & \multicolumn{5}{|c|}{0.176} \\
\hline SP1 & SP2 & SP3 & IQ1 & IQ2 & IQ3 & EP1 & EP2 & EP3 & EP4 & EP5 \\
\hline 0.324 & 0.350 & 0.325 & 0.349 & 0.338 & 0.314 & 0.202 & 0.213 & 0.190 & 0.206 & 0.189 \\
\hline \multicolumn{11}{|c|}{ (b) } \\
\hline \multicolumn{4}{|c|}{ IS } & \multicolumn{5}{|c|}{ RC } & & \\
\hline \multicolumn{4}{|c|}{0.172} & \multicolumn{5}{|c|}{0.247} & & \\
\hline IS1 & IS2 & IS3 & IS4 & RC1 & RC2 & $\mathrm{RC} 3$ & RC4 & RC5 & & \\
\hline 0.265 & 0.236 & 0.250 & 0.249 & 0.207 & 0.189 & 0.200 & 0.201 & 0.202 & & \\
\hline
\end{tabular}

Note: SP: social policy; IQ: institutional quality; EP: economic policy; IS: industry details; RC: regional characteristics.

After calculation and analysis, the regions with the highest policy risk level of industrial heritage were the Northwest and Southwest, and the policy risk index reached 52 . The region with the lowest level of policy risk was North China, where the policy risk index was only 11 . The national regional risk index ranged from 11 to 52 , and the average policy risk index was 39 .

As shown in Table 8, the first set of data shows that the scores of all the components except regional characteristics $(R C)$ in Northeast China were significantly lower than those in other regions, and the policy risk index reached 49 , corresponding to the high-level risk level, ranking third in China. In the second set of data, the East China region performed moderately in terms of social politics (SP), institutional quality (IQ), economic policy (EP), and regional characteristics (RC), but obtained the highest score in terms of industry details (IS), and the risk level of the whole region is in the middle of the national level. In the third set of data, North China, as the region with the highest policy score and the lowest policy risk index, received the highest scores for each component except the regional characteristics (RC). In the fourth set of data, compared with the poor performance in terms of institutional quality (IQ) and economic policy (EP), southern China scored highly in terms of sociopolitical (SP), industrial detail (IS), and regional characteristics (RC), achieving a moderate policy risk rating. In the fifth group of data, although the Southwest region performs moderately in terms of social politics (SP), industry details (IS), and regional characteristics (RC), the system quality and economic policy scores are quite low, ranking at the bottom of the national scale, which largely determines the high-risk level of the region. In the sixth set of data, the Northwest region received the lowest scores and the highest risk levels, which were manifested in three components: social politics (SP), institutional quality (IQ), and economic policy (EP). The scores of the above components were significantly lower than those of other regions.

Table 8. Policy risk index and regional risk level.

\begin{tabular}{ccccccccc}
\hline Working Regional Segment & SP & IQ & EP & IS & RC & Score & PRI & Risk Level \\
\hline Northeast & 32 & 20 & 25 & 76 & 92 & 51 & 49 & High \\
\hline East China & 41 & 50 & 61 & 91 & 83 & 65 & 35 & Medium \\
\hline North China & 97 & 85 & 88 & 91 & 84 & 89 & 11 & Low \\
\hline South China & 62 & 38 & 57 & 90 & 81 & 67 & 33 & Medium \\
\hline Southwest & 38 & 16 & 28 & 72 & 76 & 48 & 52 & High \\
\hline Northwest & 33 & 15 & 30 & 78 & 78 & 48 & 52 & High \\
\hline
\end{tabular}

Note: SP: social policy; IQ: institutional quality; EP: economic policy; IS: industry details; RC: regional characteristics. 


\subsection{Components in the Risk Assessment Model}

\subsubsection{Factor 1: Social Politics}

Social politics consists of three factors: geopolitics (SP1), political violence (SP2), and political stability (SP3). The component accounts for $24 \%$ of the policy risk of industrial heritage renewal.

Geo-politics is the overall description of the relationship between the spatial distribution of human social and political phenomena and the geographical environment. It focuses on analyzing the relationship between the structure and function of political regions and political regions. It reflects the influence of the geographical environment and climate factors on policy systems and people's political behavior [26,27]. On the one hand, the renewal of industrial heritage requires a rich experience in dealing with environmental and cultural issues in different regions, which is conducive to sharing the competitive advantages of different regions and expanding development channels and markets. On the other hand, industrial heritage needs to formulate and update strategies for regional policies to improve its competitive advantages, especially in regions with imperfect policy setting and relatively weak infrastructure construction levels. Political violence refers to activities in which political actors exert organized material forces against ruling relations for specific political purposes, threatening and injuring themselves, others, groups, or society, thereby producing major political consequences [28]. Political violence takes many forms, such as ethnic conflicts, terrorism, and religious conflicts. These conflicts can seriously affect the policies and institutions of the construction market or related markets. Furthermore, social stability controls social conflicts within a certain order, so that the society maintains dynamic order and continuity. Specifically, political stability refers to the absence of overall political turmoil and social unrest, and there will be no sudden qualitative changes in the regime. Policy guidance and social environment stability are not only a strong support of urban construction and industrial heritage renewal but also the foundation and guarantee of industrial development. Political stability-level industrial heritage renewal policy is closely related to the legal system.

\subsubsection{Factor 2: Institutional Quality}

The quality of the system is composed of three factors, namely legal rules (IQ1), government efficiency (IQ2), and corruption control (IQ3), which together comprise $17 \%$ of the policy risk of industrial heritage renewal.

According to North, institutional quality reflects the capacity of the government and the strength of its ability to provide rules for business activities. From the perspective of understanding the differences between different systems, explaining the reasons for the construction of these systems and studying their advantages and disadvantages for the development of the industry and economic growth, the analysis and discussion of institutional quality cannot be ignored [29]. At present, industrial heritages around the world are facing serious threats caused by destruction, abandonment, and predatory development. Industrial heritage is an evidence of social change and the product of the industrial age. Its renewal and transformation cannot be separated from a good administrative environment. Incomplete formulation of policy systems or poor policy quality, such as the ineffective implementation of rules, low government efficiency, and unfavorable control of corruption, cannot guarantee the rights and interests of industrial heritage renewal projects. Rao et al. said that a weak system of judicial enforcement uncertainty may lead to a public loss of confidence in the judicial system, forcing citizens to choose other ways to solve problems, thereby breeding the spread of corruption [30]. The research shows that the influence of policy institutions on industry development and economic growth is significantly higher than that of political participation. This will help the government curb corruption, improve the efficiency of public management, and ultimately consolidate its competitiveness and development prospects [31]. Therefore, improving governance capacity and institutional quality are conducive to shared growth, meaning that the benefits of industrial heritage renewal can benefit more people. 


\subsubsection{Factor 3: Economic Policy}

Economic policy comprises five aspects, namely land policy (EP1), profit and tax policy (EP2), investment freedom (EP3), financial freedom (EP4), and trade freedom (EP5). The total proportion of this component is $18 \%$.

Land policy refers to the code of action stipulated in the development, utilization, governance, protection, and management of land resources according to the political and economic tasks in a certain period of time [32,33]. It is an important adjustment means of dealing with various contradictions in land relations. Under the new normal situation of China's economy, the land property and increment of industrial heritage is a key and controversial topic. Land must adapt to social development and make corresponding changes. The essence of profit and tax policy is to participate in and regulate the material interests of the market economy subject [34], such as the appropriate use of tax regulation, land income rights, and other policy tools to widely increase the market enthusiasm for the renewal of industrial heritage and the absorption of private capital. Financial performance is an important indicator of competitive advantage. The economic indicators of the project reflect the differences of regional characteristics, the demands of specific market segments, time, warranty period, and other factors. The level of financial freedom can ensure the investment intensity and efficiency of the project. Reasonable investments can be balanced between low costs and high returns [35]. Investment liberalization and trade liberalization are the most substantial contents of economic globalization. Regional investment freedom, financial freedom, and trade freedom are more susceptible to policy risk [36]. Research shows strong correlations between economic policies. For the renewal of industrial heritage, restrictions on land ownership and industrial investment will hinder the protection and development of industrial heritage. Moreover, projects involving the introduction of foreign capital are likely to be subject to greater interference due to low levels of trade liberalization.

\subsubsection{Factor 4: Industry Specifics}

Industry details are defined from four aspects: industry maturity (IS1), industry return rate (IS2), local market size (IS3), and local market experience (IS4), with a total proportion of $17 \%$.

The research by Deng et al. shows that industry maturity refers to the degree of providing transparent information and regulating market behaviors [37]. The industry cycle of industrial heritage renewal has entered the growth period; the capital structure is relatively stable and has gradually won the market preference with its own characteristics. There has been a corresponding series of changes on the supply side. Therefore, the industry also faces great competition risks, such as a high bankruptcy rate and merger rate, further aggravating policy interference and market uncertainty.

A large number of traditional industries have suffered from industrial decline and industrialization. Industry returns plummeted as industrial estates were abandoned or demolished. With the renewal of industrial heritage, a good atmosphere is gradually formed, showing a wide range of utilization space, which is different to other cultural heritage. Reshaping regional competitiveness and attractiveness has been a positive way to resist the invasion of policy risks. The local market effect refers to the region that has a relatively large demand for increasing returns on scale products, which will create a larger proportion of output. In other words, relatively large areas of the two regions will be net exporters for industries with increasing returns on scale at the manufacturer level [38]. The scale and experience of the local industrial heritage renewal market can effectively help in understanding the local business environment and construction environment, identifying and giving play to the potential market's demand-scale advantages, and guide the regional industrial development and layout, improve the supply structure and improve the effective supply capacity to reduce policy risks. 


\subsubsection{Factor 5: Regional Characteristics}

Regional characteristics are embodied in five aspects: regional unemployment rate (RC1), regional gross domestic product (RC2), regional economic adaptability (RC3), regional cultural adaptability (RC4), and public satisfaction (RC5), accounting for $25 \%$ of the total.

Regional characteristics are an important source of policy risk. Regional characteristics determine regional economic performance. This reflects the low saturation of the industry and the huge demand for development [39]. Similarly, high unemployment and low GDP growth have kept enthusiasm low for infrastructure and urbanization processes. A lack of development momentum and industry expansion capacity may lead to policy risks.

Industrial heritage has witnessed the driving effect of industrial development on economic society and the protection process of social and cultural inheritance [40]. On the one hand, protecting industrial heritage can play an important role in the economic revitalization of urban areas in decline. Based on regional cultural characteristics and the economic environment, industrial heritage is reorganized and classified to maintain the continuity of regional cultural vitality. On the other hand, the international community is constantly encouraging a diverse understanding of the concept of cultural heritage and assessing the importance of its value. People have begun to realize that industrial heritage should be regarded as an integral part of cultural heritage in the general sense; however, at the same time, the preservation and renewal of industrial heritage is also facing the impact of regional economic and cultural differences. This makes the maintenance and development of industrial heritage more fragile and vulnerable to policy risks.

Public satisfaction is the emotional response of the public. Public satisfaction is based on the subjective experience of the public. The subjective experience of the public is closely related to the public's knowledge, experience, social class, living habits, and values [41], and it is therefore subjective; that is, public satisfaction is the result of comparing expectations with hindsight. The experience and impression brought by industrial heritage itself is a dynamic and comprehensive psychological experience. With the change of time, space and people's preferences, the variable structure of satisfaction will be constantly adjusted.

\subsection{Positioning of Risk Factors}

These factors are used to assess the policy risks of industrial heritage renewal projects. This paper quantifies the policy risks of specific renovation projects through calculation and evaluation. A high score means a higher risk, while a low score means more development opportunities for a project. To develop targeted countermeasures, the above five types of factors can be divided into macro-factors and micro-factors. Macro-factors include social politics (SP), institutional quality (IQ), and economic policy (EP). These reflect the external construction environment in which the industrial heritage renewal project is located. To a large extent, they determine the policy risks of the project, such as political violence (SP2), the rule of law (IQ1), Government efficiency (IQ2), etc., accounting for a total of 0.58. Micro-factors include industry details (IS) and regional characteristics (RC), such as industry maturity (IS1), local market size (IS3), adaptation to the regional economy (RC3), etc., with a total proportion of 0.419 . These represent the internal environmental characteristics of the project and the construction differences caused by different locations, such as the fiscal subsidy policies for specific places and the boosting policies for cultural and recreational industries.

However, macro-factors and micro-factors were not completely separated, but were closely linked and interact with each other, as shown in Figure 4. For Chinese industrial heritage renewal projects, industry details (IS) and regional characteristics (RC) depend on domestic political and economic systems. For example, the state's major policies and guidelines on the phased planning of the construction industry will affect the renewal and development of industrial heritage. Accordingly, the construction and presentation effects of industrial heritage renewal projects have formed a powerful impetus to promote the revision of policies on related industries and the renovation of old industrial buildings. For example, the success of the Beijing 798 recreational industry park promotes the 
formulation and implementation of Beijing's industrial heritage policies. With the different scores of macro-factors and micro-factors of industrial heritage projects, they interact with each other to form the specific risk layout of a specific project and then determine the different emphasis of developing risk countermeasures.

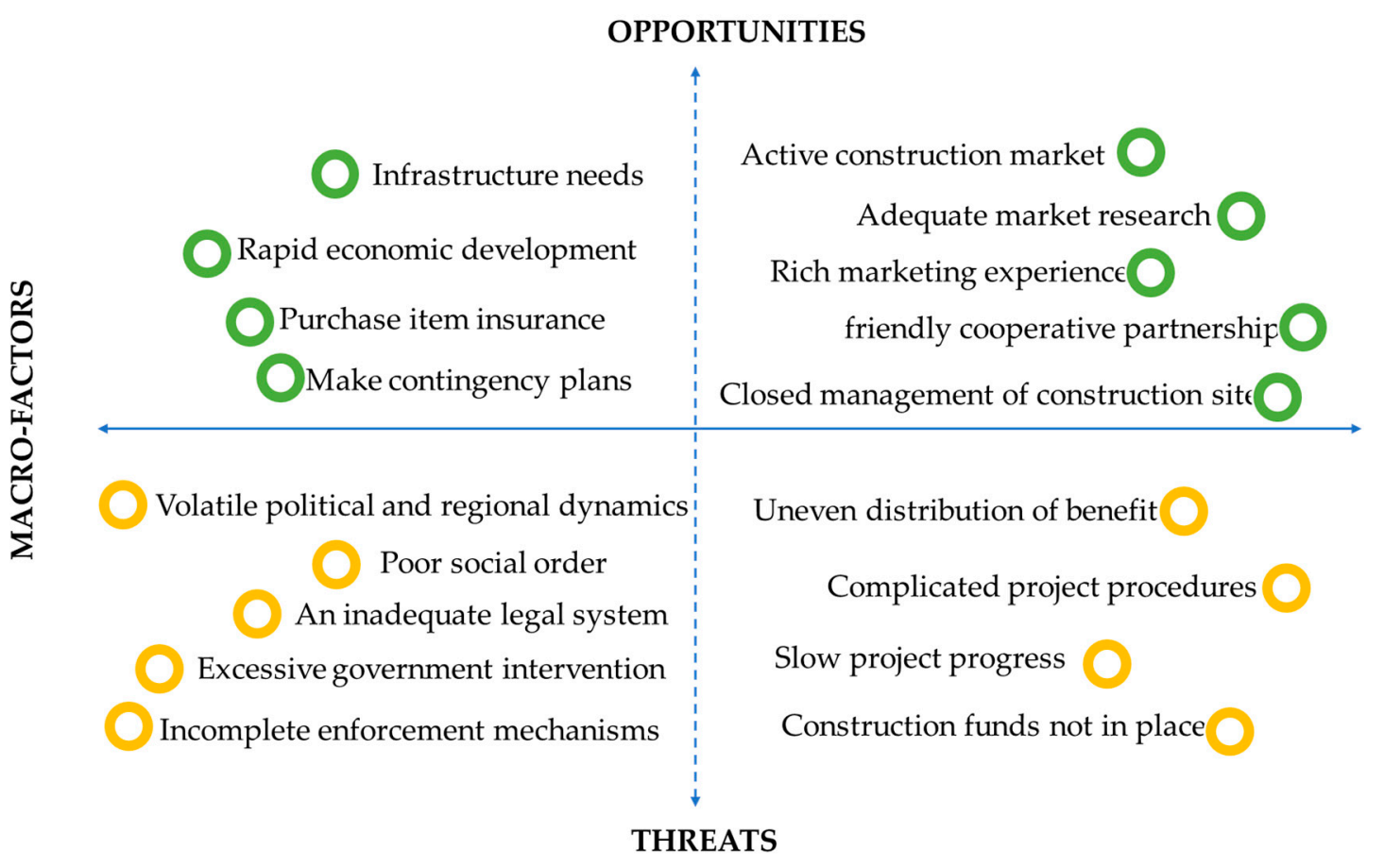

Figure 4. Opportunity and challenge analysis chart.

\section{Conclusions}

Policy risk has always been a key issue in industrial heritage renewal projects, which leads to the project stakeholders needing to reduce the exposure degree of policy risk in order to survive and develop. This paper summarized a large number of studies trying to determine the key variables that affect the policy risk index of industrial heritage renewal and preliminarily identified 20 indicators that affect the policy risk index of industrial heritage projects. Then, extensive research was conducted in six regions of the country through questionnaires, and the importance was strictly examined. It was unnecessary and unrealistic for management to control all relevant variables to reduce their impact on policy risk. Therefore, the main components that make up the policy risk index were determined by confirmatory factor analysis; i.e., social politics (SP), institutional quality (IQ), economic policy (EP), industry details (IS), and regional characteristics (RC). The above five factor groups were the basic factors affecting the policy risks of industrial heritage renewal projects. Then, we sorted the load coefficients of each observation variable, and the results showed that the first six variables were: (1) industry maturity (IS1), (2) tax policy (EP2), (3) financial freedom (EP4), (4) the rule of law (IQ1), (5) local market size IS3, and (6) local market experience (IS4). They are also critical policy risk factors that need to be focused and controlled. These factors should be considered in order to manage projects more scientifically and rationally. Finally, the policy risk levels of industrial heritage renewal in six regions were comprehensively evaluated from the overall perspective. At the same time, a new industrial heritage project risk assessment model was provided to determine the risks and opportunities faced by a project. This contributes to the protection and renewal of industrial heritage and provides a corresponding strategic approach to some extent.

First of all, compared with previous studies, this study has shown great value in theory. This paper clarifies the reasons that affect the risk of China's industrial heritage policy in many aspects and details the composition of each component. It also quantifies and ranks them according to their 
importance. It will provide a strong reference for the research of other scholars. Secondly, this research has three very important practical implications. (1) The three components at the macro level, including social politics (SP), institutional quality (IQ), and economic policy (EP), are the main causes of policy risks. (2) From the micro level of policy risk, industry details (IS) and regional characteristics (RC) are important determinants of policy risk. (3) According to the political risk situation shaped by multiple components, appropriate strategies and measures can be derived and initiated to improve policy risk management in industrial heritage renewal projects. Last but not least, this paper once again emphasizes that the major issues facing our times are not new projects, but legacy industrial buildings regeneration projects. As mentioned above, compared with ordinary new projects, industrial heritage renewal projects have higher public attention and policy sensitivity. It should be noted that although this paper has produced a number of results, its most important contribution is probably that it has drawn attention to policy risks. In this process, standards and policies that may have been ignored or ignored were addressed and openly discussed among stakeholders.

The study found that the risk level of the industrial heritage renewal project in the Chinese market is moderate. Economic policy (EP), industry details (IS), regional characteristics (RC), etc. performed well; however, social politics (SP), institutional quality (IQ), and economic policy (EP) performed poorly. According to the results of quantitative analysis and cluster analysis, the policy risk levels in Northeast China, Southwest China, and Northwest China were high, the policy risk levels in East China and South China were medium, and the policy risk level in North China was low. The demand for infrastructure construction in the six major regions was huge, and the industrial heritage renewal project had a great development foundation and potential. However, there were similar problems in the six major regions at the same time, such as legal rules, government efficiency, and corruption control. Industrial heritage renewal projects in Northeast, Southwest, Northwest, and East China must address risks associated with imperfect economic policies; industrial heritage renewal projects in the Northeast, Southwest, and Northwest must manage additional risks due to institutional efficiency and enforcement, and the Northeast, Southwest, and Northwest must limit additional risks in terms of land and tax policies and economic freedom. Choosing the right projects, conducting comprehensive social research, and developing appropriate strategies can make industrial heritage renewal projects better able to withstand risks and seize opportunities. Various measures such as selecting appropriate partners, formulating a policy insurance system, setting up a risk prevention and control system, making an emergency response plan, and localization are all effective means to prevent policy risks.

This paper focused on the risk factors related to the environment of industrial heritage construction. The industry details (IS) and regional characteristics (RC) were mainly discussed in the industrial heritage renewal market of six regions in China. The influence factors at the international level were not discussed, which was the limitation of this paper. Specific development projects should be analyzed and discussed in the practice of policy risk management. In the future, the research direction will focus on the impact of domestic and foreign policy and institutional risks on the renewal of industrial heritage, and select typical cases of different types and periods for review and verification. The application in other countries does not need major modifications, but parameters may need to be adjusted according to the specific situation and data availability of the study area to adapt to different local environments. In addition, future research will move towards developing a visual risk assessment process to communicate the final results to stakeholders in a more direct and effective manner. The web-based design and utilization of standard software solutions allows for an easy uptake and communication of the assessments. This will provide a better understanding of the relationship between input and output variables and will support decision makers to properly consider and use the results.

Author Contributions: P.G. and Y.Z. (corresponding author) were the principal researchers of this study. They were responsible for all work including the research design and development and data analysis. H.L. was responsible for setting the overall research objectives. G.Z. managed activities to annotate, scrubbed data and maintained research data for initial use and later re-use. 
Funding: This research was funded by the NSFC (51908452, 51808424, 51677879, 51478384), Foundation of MOHURD (2018-R1-009) Natural Science Foundation of Shaanxi Provincial Department of Education (18JK0458) and Youth Science and Technology Fund of Xi'an University of A\&T (RC1726).

Conflicts of Interest: The authors declare no conflict of interest.

\section{References}

1. Gao, B.Y.; Liu, W.D.; Dunford, M. State land policy, land markets and geographies of manufacturing: The case of Beijing, China. Land Use Policy 2014, 36, 1-12.

2. Gao, J. Urban land expansion and structural change in the Yangtze river delta, China. Sustainability 2015, 7, 10281-10307. [CrossRef]

3. The State Council. Several Pinions of the CPC Central Committee and the State Council on Further Strengthening the Management of Urban Planning and Construction. Available online: http://www.chinawaterrisk.org/research-reports/opinions-on-further-strengthening-urban-planningand-construction-management/ (accessed on 16 November 2019).

4. Wang, X.; Wang, S. Chairman's government background, excess employment and government subsidies: Evidence from Chinese local state-owned enterprises. China J. Account. Res. 2013, 6, 51-74.

5. He, S.; Wu, F. China's emerging neoliberal urbanism: Perspectives from urban redevelopment. Antipode 2010, 41, 282-304. [CrossRef]

6. Li, W.; Xu, X.; Chen, K. Redtory Will "Partially Retain, Partially Develop". Available online: http: //epaper.oeeee.com/epaper/A/html/2015-12/10/content_19672.htm (accessed on 15 November 2019).

7. Zhao, X. The Industrial Heritage Has Been Reborn. Available online: http://paper.people.com.cn/rmrbhwb/ html/2009-06/23/content_280558.htm (accessed on 16 November 2019).

8. People's Daily Online. Wuhan's Industrial Heritage Will Be Demolished to Make Way for Real Estate. Experts Say the Gain Is Not Worth the Loss. Available online: http://www.people.com.cn/GB/192245/194843/ 12212431.html (accessed on 16 November 2019).

9. Hu, F.Z.Y.; Lin, G.C.S. Placing the transformation of state-owned enterprises in northeast china: The state, region and firm in a transitional economy. Reg. Stud. 2013, 47, 563-579. [CrossRef]

10. Howell, L.D.; Chaddick, B. Models of political risk for foreign investment and trade: An assessment of three approaches. Columbia J. World Bus. 1994, 29, 70-91. [CrossRef]

11. Ozorhon, B.; Arditi, D.; Dikmen, I.; Birgonul, M.T. Effect of host country and project conditions in international construction joint ventures. Int. J. Proj. Manag. 2007, 25, 799-806. [CrossRef]

12. Chen, G.H.; Zhang, J.; Zhang, H.; Yan, W.W.; Chen, Q.G. Study on regional risk assessment methodology. China Saf. Sci. J. 2006, 16, 112-117.

13. Baloi, D.; Price, A.D.F. Modelling global risk factors affecting construction cost performance. Int. J. Proj. Manag. 2003, 21, 261-269. [CrossRef]

14. Deng, X.; Sui, P.L. Exploring Critical Variables That Affect Political Risk Level in International Construction Projects: Case Study from Chinese Contractors. J. Prof. Issues Eng. Educ. Pract. 2014, 140, 04013002. [CrossRef]

15. Maor, M. Policy persistence, risk estimation and policy underreaction. Policy Sci. 2014, 47, 425-443. [CrossRef]

16. Group, T.P. International Country Risk Guide (ICRG) Methodology. 2016. Available online: http://www. prsgroup.com/explore-our-products/international-country-risk-guide (accessed on 9 June 2019).

17. ISO/TC 262 Risk Management. Available online: https://www.iso.org/committee/629121/x/catalogue/ (accessed on 18 November 2019).

18. Likert, R. A technique for the measurement of attitudes. Arch. Psychol. 1932, 22, 1-55.

19. Fu, H.; Wang, M.; Li, P.; Jiang, S.; Hu, W.; Guo, X.; Cao, M. Tracing Knowledge Development Trajectories of the Internet of Things Domain: A main path analysis. IEEE Trans. Ind. Inform. 2019. [CrossRef]

20. Minglong, W. Structural Equation Model-Operation and Application of AMOS; Chongqing University Press: Chongqing, China, 2017.

21. Hair, J.F.; Black, W.C.; Babin, B.J.; Anderson, R.E.; Tatham, R.L. Multivariate Data Analysis, 5th ed.; Prentice Hall: Upper Saddle River, NJ, USA, 1998.

22. Fornell, C.; Larcker, D.F. Evaluating structural equation models with unobservable variables and measurement error. J. Mark. Res. 1981, 18, 39-50. [CrossRef] 
23. Fu, H.; Manogaran, G.; Wu, K.; Cao, M.; Jiang, S.; Yang, A. intelligent decision-making of online shopping behavior based on internet of things. Int. J. Inf. Manag. 2020, 50, 515-525. [CrossRef]

24. Jackson, D.L.; Gillaspy, J.A.; Purc-Stephenson, R. Reporting practices in confirmatory factor analysis: An overview and some recommendations. Psychol. Methods 2009, 14, 6-23. [CrossRef]

25. Isaac, I. Training in risk management. Int. J. Proj. Manag. 1995, 13, 225-229. [CrossRef]

26. Lu, C.; Wu, Y.; Shen, Q.; Wang, H. Driving force of urban growth and regional planning: A case study of China's Guangdong Province. Habitat Int. 2013, 40, 35-41. [CrossRef]

27. Cowen, D.; Smith, N. After geopolitics? From the geopolitical social to geoeconomics. Antipode 2010, 41, 22-48. [CrossRef]

28. Besley, T.; Persson, T. The Logic of Political Violence. Q. J. Econ. 2011, 126, 1411-1445. [CrossRef]

29. North, D.C. Institutions, Institutional Change and Economic Performance; Cambridge University Press: Cambridge, UK, 1990.

30. Rao, A.N.; Pearce, J.L.; Xin, K. Governments, reciprocal exchange and trust among business associates. J. Int. Bus. Stud. 2005, 36, 104-118. [CrossRef]

31. Wu, J. From Authoritarain Developmentalism to Democratic Developmentalism; Citic Press: Beijing, China, 2008.

32. Needham, B.; Louw, E.; Metzemakers, P. An economic theory for industrial land policy. Land Use Policy 2013, 33, 227-234. [CrossRef]

33. Ding, C. Land policy reform in China: Assessment and prospects. Land Use Policy 2003, 20, 109-120. [CrossRef]

34. Devereux, M.P.; Griffith, R. Evaluating tax policy for location decision. Int. Tax Public Financ. 2003, 10, 107-126. [CrossRef]

35. Amtenbrink, F. Securing Financial Independence in the Legal Basis of a Central Bank; Social Science Electronic Publishing: Rochester, NY, USA, 2005.

36. Egger, P.; Larch, M.; Pfaffermayr, M. On the welfare effects of trade and investment liberalization. Eur. Econ. Rev. 2007, 51, 669-694. [CrossRef]

37. Deng, X.; Pheng, L.S. Understanding the critical variables affecting the level of political risks in international construction projects. Ksce J. Civ. Eng. 2013, 17, 895-907.

38. Head, K.; Mayer, T. Chapter 59-The empirics of agglomeration and trade. Handb. Reg. Urban Econ. 2004, 4, 2609-2669.

39. Stuetzer, M.; Obschonka, M.; Brixy, U.; Sternberg, R.; Cantner, U. Regional characteristics, opportunity perception and entrepreneurial activities. Small Bus. Econ. 2014, 42, 221-244. [CrossRef]

40. Kono, T. Intangible cultural heritage and intellectual property: Communities, cultural diversity and sustainable development. Int. J. Minority Group Rights 2009, 17, 387-389.

41. Fornell, C. The American customer satisfaction index: Nature, purpose, and findings. J. Mark. 1996, 60, 7-18. [CrossRef]

(C) 2019 by the authors. Licensee MDPI, Basel, Switzerland. This article is an open access article distributed under the terms and conditions of the Creative Commons Attribution (CC BY) license (http://creativecommons.org/licenses/by/4.0/). 